\title{
Comparison of conventional and wide field direct ophthalmoscopy on medical students' self-confidence for fundus examination: a 1-year follow-up
}

Gabriel Ayub ${ }^{*}$ (D), Rafael Boava Souza, Andrelisa Marina de Albuquerque and José Paulo Cabral de Vasconcellos

\begin{abstract}
Background: Fundus examination is an easy, quick and effective way to diagnose sight- and life-threatening diseases. However, medical students and physicians report lack of proficiency and self-confidence in perform fundoscopy. The aim of this study was to compare students' self-confidence in fundus examination, using two different direct ophthalmoscopes, 1 month and 1 year after practical training.

Methods: In this prospective cohort, medical students (MS) of the same class were divided in small groups for PanOptic (PO) or conventional (CO) direct ophthalmoscope training. The intervention group encompassed MS of the 4th -year (class of 2019), and the control group encompassed MS of year behind (class of 2020). A questionnaire to measure self-confidence in fundoscopy technique assessing optic nerve, cup-to-disc ratio and macula was translated and validated to Portuguese, and applied 1-month and 1-year after practical training.

Results: One-hundred and sixty-seven MS were enrolled (35 PO group, 38 CO group, and 94 control group). PO group had a significantly higher overall self-confidence comparing either control or CO groups, respectively (3.57 \pm 0.65 vs. $2.97 \pm 1.03$ vs. $2.46 \pm 0.87, p<0.01)$ as well as in evaluate cup-to-disc ratio ( $3.09 \pm 0.75$ vs. $2.32 \pm 0.87$ vs. $1.46 \pm 0.81, p<0.01$ ), optic disc margins ( $3.26 \pm 0.85$ vs. $2.71 \pm 0.96$ vs. $2.01 \pm 0.97, p<0.01)$ and macula (3.43 \pm 1.12 vs. $2.89 \pm 1.08$ vs. $2.02 \pm 0.89, p<0.01) 1$-month after practical training. One-year after intervention, CO group showed a significantly higher score compared to PO group in overall self-confidence (3.31 \pm 0.69 vs. $3.18 \pm 0.73, p=$ $0.03)$ and in optic disc margins assessing ( $3.16 \pm 0.85$ vs. $2.95 \pm 0.78, p=0.03)$, but not significant in the evaluation of cup-to-disc ratio ( $2.78 \pm 0.97$ vs. $2.68 \pm 0.94, p=0.08$ ), and macula ( $3.34 \pm 0.79$ vs. $3.27 \pm 0.98, p=0.07$ ).

Conclusions: Students were more confident in use PO as an instrument to perform direct ophthalmoscopy immediately after practical training, but confidence level of CO was higher compared to PO one year after practical training. These findings would help medical schools decide which ophthalmoscope to choose to teach fundus examination.
\end{abstract}

Keywords: Direct ophthalmoscopy, Fundus examination, Self-confidence, Medical student education, Questionnaire validation

\footnotetext{
* Correspondence: gabriel.ayub@gmail.com

Department of Ophthalmology, Faculty of Medical Sciences, University of

Campinas, 251 Vital Brazil St, SP 13083-888 Campinas, Brazil
}

(C) The Author(s). 2021 Open Access This article is licensed under a Creative Commons Attribution 4.0 International License, which permits use, sharing, adaptation, distribution and reproduction in any medium or format, as long as you give appropriate credit to the original author(s) and the source, provide a link to the Creative Commons licence, and indicate if changes were made. The images or other third party material in this article are included in the article's Creative Commons. licence, unless indicated otherwise in a credit line to the material. If material is not included in the article's Creative Commons licence and your intended use is not permitted by statutory regulation or exceeds the permitted use, you will need to obtain permission directly from the copyright holder. To view a copy of this licence, visit http://creativecommons.org/licenses/by/4.0/. The Creative Commons Public Domain Dedication waiver (http://creativecommons.org/publicdomain/zero/1.0/) applies to the data made available in this article, unless otherwise stated in a credit line to the data. 


\section{Background}

Reversible blindness has been increasing worldwide. In 2020 was estimated that 237 million people had moderate to severe vision impairment, while 38 million were blind [1]. The leading causes were refractive errors, cataract, glaucoma, age-related macular degeneration and diabetic retinopathy [1]. A strategy to provide eye care and early diagnosis would reduce the burden of reversible blindness worldwide.

Fundus examination is still an easy, quick and effective way to diagnose sight- and life-threatening diseases in emergency [2] and primary-care environments [3-6]. A plenty of devices are available for fundus examination: indirect ophthalmoscopy, retinography, direct ophthalmoscopy, and more recently, smartphone-based ophthalmoscopy (SF) [7]. Indirect ophthalmoscopy demands more training time and additional instruments to perform fundus examination; although the emergence of $\mathrm{SF}$, it remains a high-cost examination [7]. The International Council of Ophthalmology $[8,9]$ and the Association of University Professors of Ophthalmology [10] recommend teach fundus examination to medical students (MS) for a proficiency in handling the device, direct ophthalmoscope, and identify normal and abnormal fundus and optic nerve head. Despite recommendations, the art of fundoscopy has been forgotten [11] due to a crowded curriculum in medical schools, which reduced the time of ophthalmology rotation [12], fall of ownership of ophthalmoscopes [13] and no consensus on minimum ophthalmoscopy proficiency [14, 15], which results in a lack of knowledge and self-confidence in perform fundoscopy by general practitioners [5, 16-20].

Among direct ophthalmoscopes devices, wide field ophthalmoscope provides a larger field of view and an increased magnification compared to conventional ophthalmoscope. Besides, some studies have reported to be easier to use it in fundus examination $[2,21]$. A major disadvantage of wide field ophthalmoscope, however, is its higher price compared to conventional devices.

Some studies have addressed the apprenticeship of the ophthalmoscopy exam during the MS graduation. They have observed an increase in MS's knowledge and self-confidence soon after a practical training [18, $22]$, but both seems to decrease with time [19, 20, 23]. A longer follow-up would address the effectiveness of hands-on fundoscopy to recognize the most relevant structures in fundus examination. In addition, MS' self-confidence in conducting fundus examination with different ophthalmoscopes, such as a wide-field, was not investigated one year after a practical training, according to our knowledge. The aim of our study was to evaluate students' self confidence in two different ophthalmoscope devices 1 month and 1 year after practical training.

\section{Methods}

This prospective cohort study was approved by the Research Ethics Committee of the University of Campinas and conducted in compliance with the Declaration of Helsinki. All procedures were fully explained and an informed consent was obtained from all participants.

Participants were recruited from July/2019 to January/ 2020 and a new one-year evaluation was done between October/2020 and November/2020.

\section{Inclusion and exclusion criteria}

For contextualization, the undergraduate medicine course in Brazil takes 6 years. At University of Campinas the course is divided in two moments: second year (basic rounds) and fourth year (clinical rounds). The basic rounds consist of theoretical lectures, which exposes the anatomy, physiology and histology of the eye and the vision, in a total of $6 \mathrm{~h}$. The clinical rounds also consist of theoretical lectures, focused on basic eye exam and pathologies, and a basic practical training on physical examination of the eye on slit lamp, visual acuity check, fundus examination and surgical observation, encompassing all sub-specialties of the ophthalmology (retina, cornea, glaucoma, ocular plastics, strabismus, neuroophthalmology), in total of $36 \mathrm{~h}$. Students are divided in subgroups of 6-7 persons for this practical training.

For classes in fundus examination, the intervention group included all MS of the 4th -year (class of 2019 at Faculty of Medical Sciences, University of Campinas). For the control group, all MS of the 4th -year (class of 2020 at Faculty of Medical Sciences, University of Campinas) were invited to participate. MS with either previous experience on managing an ophthalmoscope or students that missed the fundus examination classes as well as those who did not accept participate were excluded.

The ophthalmoscopes we used to teach fundus examination were a conventional ophthalmoscope (Coaxial, Welch Allyn, Skaneateles Falls, NY, USA) and a wide field ophthalmoscope (PanOptic, Welch Allyn, Skaneateles Falls, NY, USA). Briefly, PanOptic is a wide field ophthalmoscope, which provides a $5 \mathrm{x}$ larger field of view than conventional Coaxial ophthalmoscope $\left(25^{\circ}\right.$ versus $5^{\circ}$ ) and a $26 \%$ increase in magnification. Also, PanOptic can be used in non-mydriatic patients.

\section{Questionnaire translation and cross-cultural validation}

We included residents from first- to fourth-year for the questionnaire translation and validation. The questionnaire developed by Haque et al. [24] was used as basis. This questionnaire was design and validated to rank student's confidence in identify eye fundus structures as disc margins, cup-to-disc ratio, macula and the overall confidence on using the ophthalmoscope, based on a 
Likert scale ranked from 1 (low confidence) to 5 (extreme confidence).

The process for translation and cross-cultural validation was previously described by several authors [2528]. First, the basis questionnaire was translated from English to Portuguese by 2 native Portuguese speakers. The translated questionnaire was then evaluated by a committee composed by 2 ophthalmologists and 2 MS to ensure an adequate translation and cross-cultural validation. Later, 2 native English speakers back translated the questionnaire from Portuguese to English, which was then re-checked by the committee.

Finally, we applied the Portuguese version of the questionnaire in a group of first- to fourth-year ophthalmology residents. Internal consistency, to evaluate the inter-correlation of the questionnaire items, was calculated using coefficient alpha (Cronbach's alpha $\alpha)$, which varies from 0 to 1 , and a value $>0.7$ is considered adequate [27]. One week later, the questionnaire was re-applied on the same group to verify test-retest reliability, calculated by Pearson correlation (R), and inter-rater reliability, calculated by Cohen's Kappa (к), which varies from 0 to 1 , and is classified as: $<0.2$, poor agreement; $0.2-0.4$, weak agreement, $0.4-0.6$, moderate agreement; $0.6-0.8$, good agreement; $>0.8$ excellent agreement $[26,27]$.

\section{Training of the participants and evaluation}

Intervention group of MS of the 4th -year/2019 were divided in 2 groups after fulfilled the inclusion criteria: one group was designated to use the Coaxial ophthalmoscope $(\mathrm{CO})$ in all the interventions, while the other, to use the PanOptic ophthalmoscope (PO).

Our intervention in teaching eye fundus examination was composed of a $6 \mathrm{~h}$ of practical training applied in subgroups containing 6-7 students. Our interventions were done by the same instructors (G.A. and J.P.C.V). First, we did a 1-h training with an initial explanation of the fundoscopy technique. Then, we used an acrylic cube model that simulates a normal eye fundus provided by Welch Allyn as first practical training of the technique, which the students could evaluate the main structures of the eye fundus (optic disc, cup-to-disc ratio, macula, vessels and retina). Later, students trained the technique among them to visualize the same structures in a normal human eye. Next, we helped students to examine dilated patients to identify normal and pathological structures, where findings compatible with diabetic retinopathy (intraretinal hemorrhages, hard exsudates, retina and optic disc neovascularization), hypertensive retinopathy (arteriovenous nicking and narrowing, cotton-wool spots), age-related macular degeneration (macular drusen) and glaucoma (increased cup- to-disc ratio) were visualized. All patients were prior evaluated by the instructor.

We applied the questionnaire in the control group at the first lecture day of the class in 2020 for a baseline of the MS confidence before intervention. The control group had the same experience in fundus examination than the intervention group before starting the 4th -year.

To check the 1-year retention of the intervention, we re-applied the same questionnaire on the same individuals of the intervention group between October $/ 2020$ and November/2020. All students where on the 5th -year at the time. Because of Covid-19 restrictions, application was virtual.

\section{Statistical analysis}

Internal consistency (Cronbach's alpha - $\alpha$ ), test-retest reliability (Person correlation - R) and inter-rater reliability (Cohen's Kappa - K) were calculated as previously described.

Descriptive data are shown in percentage and mean \pm standard deviation. Normality was assessed by QQ-Plot and inspecting a histogram. Baseline values where compared with ANOVA (age) and qui-square (gender). To compare the scores within 1-month between the intervention groups and control group, Kruskall-Wallis test was done, followed by Mann-Whitney-U test to compare each pair of groups. For this first comparison, the null hypothesis was considered as there was no difference between the groups, while the alternative hypothesis was considered as there would be a difference for one device or another (two-tailed tests). Mann-Whitney-U test was also used to compare $\mathrm{CO}$ and $\mathrm{PO}$ groups 1-year score after intervention. Moreover, Wilcoxon rank sum test was used to compared the paired scores between 1month and 1-year intervention. For these two comparisons, the null hypothesis was also considered as there was no difference between the groups 1 year later, while the alternative hypothesis was considered as there would be a difference for one device or another (two-tailed tests).

Analysis were done with Statistical Package for Social Sciences - SPSS (IBM Corporation, Armon NY, USA, version 22.0).

\section{Results}

\section{Questionnaire validation}

A total of 35 ophthalmology residents were included in the questionnaire validation process. The translated questionnaire had a strong internal consistency $(\alpha=$ 0.82 ), and a good agreement with strong correlation in the overall confidence on the fundoscopy technique question $(R=0.83, \mathrm{\kappa}=0.61, p<0.01)$ and optic disc margins question $(R=0.74, \mathrm{\kappa}=0.64, p<0.01)$. Cup-to-disc 
ratio $(R=0.78, \mathrm{\kappa}=0.51, p<0.01)$ and macula $(R=0.80$, $\kappa=0.53, p<0.01)$ questions had a moderate agreement with strong correlation [Table 1].

\section{One-month assessment}

A total of 167 MS were included: 94 in the control group, 38 in the $\mathrm{CO}$ group and 35 in the $\mathrm{PO}$ group; baseline characteristics are depicted in Table 2. Students' self-confidence score in the fundoscopy technique question was $2.46 \pm 0.87$ vs. $2.97 \pm 1.03$ vs. $3.57 \pm 0.65$ ( $p<$ 0.01 ), cup-to-disc ratio score was $1.46 \pm 0.81$ vs. $2.32 \pm$ 0.87 vs. $3.09 \pm 0.75(p<0.01)$, optic disc margins score was $2.01 \pm 0.97$ vs. $2.71 \pm 0.96$ vs. $3.26 \pm 0.85(p<0.01)$ and macula score $2.02 \pm 0.89$ vs. $2.89 \pm 1.08$ vs. $3.43 \pm$ $1.12(p<0.01)$ comparing control group, CO group and $\mathrm{PO}$ group, respectively [Table 3$]$ The PO group was superior to the control group in all the 4 question $(p<$ 0.01 ) and to the $\mathrm{CO}$ group in the fundoscopy technique $(p=0.02)$ and cup-to-disc ratio $(p=0.01)$ questions, but not in the optic disc $(p=0.13)$ and macula evaluations $(p=0.22)$ questions [Table 4]. Also, CO group had a higher score in all the 4 questions (question $1, p=0.01$; question $2, p<0.01$; question $3, p=0.01$; and question 4 , $p<0.01)$ compared to the control group.

\section{One-year assessment}

One year after the intervention, the groups were reevaluated, and $32(84.21 \%)$ students of the $\mathrm{CO}$ and 22 $(62.85 \%)$ in the PO group answered the questionnaire. Students' self-confidence score in the fundoscopy technique question was $3.31 \pm 0.69$ vs. $3.18 \pm 0.73(p=0.03)$, cup-to-disc ratio score was $2.78 \pm 0.97$ vs. $2.68 \pm 0.94$ $(p=0.08)$, optic disc margins score was $3.16 \pm 0.85$ vs. $2.95 \pm 0.78(p=0.03)$ and macula score was $3.34 \pm 0.79$ vs. $3.27 \pm 0.98(p=0.07)$ comparing $\mathrm{CO}$ group and $\mathrm{PO}$ group, respectively [Table 4].

Comparison between scores 1-month and 1-year scores were higher and statistically significant for cupto-disc ratio $(p=0.01)$, optic disc margins $(p=0.01)$ and macula evaluations $(p<0.01)$ but not for overall confidence $(p=0.22)$ in the $\mathrm{CO}$ group. In the PO group, the overall confidence was lower and statistically significant $(p=0.01)$, this did not present for cup-to-disc ratio ( $p=$
$0.09)$, optic disc margins $(p=0.56)$ and macula $(p=$ 0.64) [Table 4].

\section{Discussion}

Questionnaire translation and validation

Translation and cross-cultural validation allows comparison between results obtained in two different cultures and populations by the same instrument. The questionnaire of Haque et al. [24] was chosen due to assess main structures of the eye fundus for general practice with a short instrument. Compared to them, who enrolled 13 s-year MS and 17 residents in a crosssectional design, an overall confidence of 3.12, with the lowest score in cup-to-disc ratio, was found. Our study observed slightly lower value in $\mathrm{CO}$ and a higher value in PO group 1 month after training, and also reported the lowest confidence score in cup-to-disc ratio evaluation.

\section{The role of fundus examination in physical examination} One aspect that motivated our study was a perception in our institution of unfamiliarity of clerks, residents and general practitioners with the ophthalmoscope handling, identification of normal and pathological structures and self-confidence in perform the exam. This was investigated by Wu et al. [16], who measured the confidence of third- and fourth-year MS, first-and second-fourth-year internal medicine residents and general internists in perform 14 items of the physical examination with a 5point Likert scale. While measure blood pressure achieved the highest score $(4.4 \pm 0.7$ vs. $4.8 \pm 0.5$ vs. $4.4 \pm 0.7$ vs. $4.7 \pm 0.5$ vs. $4.9 \pm 0.2$, respectively, overall $=$ $4.7 \pm 0.6$ ), non-dilated fundoscopy had the lowest score $(2.3 \pm 1.1,2.8 \pm 1.2,2.3 \pm 1.1,2.2 \pm 1.0,3.2 \pm 1.1$, respectively, overall $=2.5 \pm 1.1$ ). Also, fundus examination had the third worst score among perceived utility, $3.7 \pm 0.9$, versus $4.9 \pm 0.3$ of measure blood pressure, the highest score, which reveals that both MS and graduated doctors have a lack of confidence and motivation to perform fundoscopy.

\section{Short-term evaluation}

At short-term, practical training in fundoscopy appears to increased MS' skills. Cordeiro et al. [18] validated a 8-

Table 1 Validation tests of the translated questionnaire. Test-retest reliability showed a strong correlation, and inter-rater reliability showed a good agreement in the fundoscopy technique and optic disc margins questions, and a moderate agreement in the cupto-disc ratio and macular evaluation question. Internal consistency was $a=0.82$

\begin{tabular}{lccc}
\hline & Pearson correlation (test-retest reliability) & Cohen's kappa (inter-rater reliability) & $\boldsymbol{P}$-value \\
\hline Question 1: fundoscopy technique & 0.83 & 0.61 & $<.01$ \\
Question 2: cup-to-disc ratio & 0.78 & 0.51 & $<\mathbf{0 . 0 1}$ \\
Question 3: optic disc margins & 0.74 & 0.64 & $<\mathbf{0 . 0 1}$ \\
Question 4: macula evaluation & 0.80 & 0.53 & $<\mathbf{0 . 0 1}$ \\
\hline
\end{tabular}


Table 2 Baseline characteristics of the groups. Values are presented as mean \pm standard deviation. P-value was calculated with ${ }^{*}$ ANOVA (age) and ${ }^{\dagger}$ qui-square (gender)

\begin{tabular}{lllll}
\hline & Control & Conventional & PanOptic & P-value \\
\hline $\mathrm{n}$ & 94 & 38 & 35 & - \\
Age (years) & $23.36 \pm 2.30$ & $24.41 \pm 5.19$ & $23.44 \pm 2.44$ & $0.24^{*}$ \\
Gender (Male/Female) & $37 / 57$ & $14 / 24$ & $17 / 18$ & $0.55^{\dagger}$ \\
\hline
\end{tabular}

question objective structured clinical examination questionnaire and assessed 29 MS skills in ophthalmoscopy before and after formal instruction. The authors measured a $23.7 \%$ increase in MS's skills $(5.3379 \pm 2.252$ vs. $7.7069 \pm 1.724, p<0.001)$. Kelly et al. [22] compared direct ophthalmoscopy examination of human volunteers and human models simulators to fundus photograph in a randomized study that enrolled 119 first-year MS. Of a 48-item questionnaire, pre-test score was $60 \%$, while post-test score was $77 \%$ for simulator and $85 \%$ for photograph group $(p<0.001)$. In addition, $71 \%$ of students preferred human volunteers to human models simulators, $77 \%$ preferred photographs to human models simulators and $70 \%$ preferred fundus photograph than use a direct ophthalmoscope. Our results show that both groups had a better performance onemonth after the practical training, which reinforces what is observed in the literature.

\section{Long-term evaluation}

Despite of an increase of MS's skills after a practical training, these seem to decrease with time. Mackay an colleagues [23] reported the 1-year follow-up of the original study of Kelly et al. previously described [22], and revealed MS's more accurate diagnosis and their preference for photograph when compared to CO. At 1-year retention study [23], out of 48 questions, students answered correctly $72 \%$ with fundus photographs and $65 \%$ with direct ophthalmoscopy $(p=0.004)$. This represented 5 fewer questions answered correctly at 1-year comparison in both groups $(p<0.001)$. A general discomfort (38\%), discouragement by preceptors $(20 \%)$ and insufficient time $(15 \%)$ were nominated as the main issues for not perform fundus exam. Also, in a 3-year follow-up study, Lippa and colleagues [19] evaluated a group of second-year MS longitudinally on third- and fourthyears after a 12-item training in eye screening skills. Of the 96 MS included in the first evaluation, $76 \% \pm 9 \%$ felt comfortable to describe at least 1 characteristic of the visualized optic disc. One year later, the 96 MS had their fundus examination skills evaluated with a human model simulator: $32 \%$ described some feature of the optic disc, but $22 \%$ were unable to described correctly a fundus of a dilated eye and $20 \%$ unable to complete the same in an undilated eye. At fourth-year, of 54 graduated, $59 \%$ felt comfortable in evaluate optic disc, $46 \%$, macula, $61 \%$, vessels and $57 \%$, retina; $11 \%$ felt very confident in fundoscopy, $65 \%$ somewhat confident, and $26 \%$ not confident. In our study, this decrease in self-confidence was observed in $\mathrm{PO}$ group, but not in $\mathrm{CO}$ group, which will be discussed next.

\section{Comparison of both devices in diagnostic accuracy}

A few studies have already compared CO and PO for accuracy in diabetic retinopathy screening [3], cup-to-disc ratio evaluation [21] and optic nerve pathologies at emergency room [2]. The first study to compare both devices enrolled 8 first-year MS for cup-to-disc ratio evaluation and ease of use. Student were assigned to use one ophthalmoscope for patient examination in one session and then swap the device for a second session ${ }^{21}$. No difference was found in cup-to-disc ratio measurement between $\mathrm{CO}$ and $\mathrm{PO}(0.08 \pm 0.14$ vs. $0.09 \pm 0.13, p=$ $0.67)$ in the first session. However, there was a significant difference in the second session regarding cup-todisc ratio $(p=0.02)$, which suggests a learning effect. Moreover, MS scored PO easier to use than CO (9 vs. 8 , $p<0.0001$ ), and dilated easier than undilated for each device, despite no difference was found when compared dilated $\mathrm{CO}$ examination versus undilated $\mathrm{PO}(p=$

Table 3 One-month score of the 3 groups in each question. Values are presented as mean \pm standard deviation. The PanOptic group was superior compared to the other groups. Kruskal-Wallis test was used to compare the groups

\begin{tabular}{lllll}
\hline & Control & Conventional & PanOptic & P-value \\
\hline Overall self-confidence & $2.46 \pm 0.87$ & $2.97 \pm 1.03$ & $3.57 \pm 0.65$ & $<.01$ \\
Cup-to-disc ratio & $1.46 \pm 0.81$ & $2.32 \pm 0.87$ & $3.09 \pm 0.75$ & $<.01$ \\
Optic disc margins & $2.01 \pm 0.97$ & $2.71 \pm 0.96$ & $3.26 \pm 0.85$ & $<\mathbf{0 . 0 1}$ \\
Macula & $2.02 \pm 0.89$ & $2.89 \pm 1.08$ & $3.43 \pm 1.12$ & $<0.01$ \\
\hline
\end{tabular}


Table 4 Comparison between 1-month and 1-year scores. Values are presented as mean \pm standard deviation. Statistically significant values are in bold. 'Wilcoxon rank sum test was used to compare the scores of medical students that completed the questionnaire in both periods, and *Mann-Whitney- $U$ test were used to compare the groups within the same period

\begin{tabular}{llll}
\hline & \multicolumn{1}{c}{ Conventional } & PanOptic & $P$-value \\
\hline Overall self-confidence & & \\
1-month & $2.97 \pm 1.03$ & $3.57 \pm 0.65$ & $\mathbf{0 . 0 2}^{*}$ \\
1-year & $3.31 \pm 0.69$ & $3.18 \pm 0.73$ & $\mathbf{0 . 0 3}^{*}$ \\
$\boldsymbol{P}$-value & $0.22^{\dagger}$ & $\mathbf{0 . 0 1}^{\dagger}$ & \\
Cup-to-disc ratio & & & \\
1-month & $2.32 \pm 0.87$ & $3.09 \pm 0.75$ & $\mathbf{0 . 0 1 ^ { * }}$ \\
1-year & $2.78 \pm 0.97$ & $2.68 \pm 0.94$ & $0.08^{*}$ \\
$\boldsymbol{P}$-value & $\mathbf{0 . 0 1 ^ { \dagger }}$ & $0.09^{\dagger}$ & \\
Optic disc margins & & & \\
1-month & $2.71 \pm 0.96$ & $3.26 \pm 0.85$ & $0.13^{*}$ \\
1-year & $3.16 \pm 0.85$ & $2.95 \pm 0.78$ & $\mathbf{0 . 0 3 ^ { * }}$ \\
$\boldsymbol{P}$-value & $\mathbf{0 . 0 1 ^ { \dagger }}$ & $0.56^{\dagger}$ & \\
Macula & & & \\
1-month & $2.89 \pm 1.08$ & $3.43 \pm 1.12$ & $0.22^{*}$ \\
1-year & $3.34 \pm 0.79$ & $3.27 \pm 0.98$ & $0.07^{*}$ \\
$\boldsymbol{P}$-value & $<\mathbf{0 . 0 1 ^ { \dagger }}$ & $0.64^{\dagger}$ & \\
\hline
\end{tabular}

$0.82)^{21}$. Another comparison was made for diagnose of optic nerve pathologies in emergency environment by Petrushkin et al. [2], which included 36 emergency doctors who examined critical patients with both devices. PO had a higher sensitivity and specificity (0.63 and $0.55)$ than $\mathrm{CO}(0.31$ and 0.30$)$, which was statistically significant ( $p=0.03$ in both comparisons); also, doctors $(p=0.001)$ and patients $(P=0.04)$ preferred $\mathrm{PO}$ over CO. In terms of diabetic retinopathy, Tan et al. [3] evaluated sensitivity and specificity of $\mathrm{PO}$ and $\mathrm{CO}$ to diagnose sight-threatening diabetic retinopathy using indirect ophthalmoscopy at slit-lamp biomicroscopy as reference. To avoid intra- and inter-rater variability, only one examiner performed all the evaluations. In a total of 200 patients, $\mathrm{CO}$ had a higher sensitivity (73.2\% vs. $58.5 \%)$, equal specificity $(93.7 \%)$, higher positive predictive value (75\% vs. $70.6 \%)$ and higher negative predictive value (93.1\% vs. $89.8 \%$ ) compared to PO, respectively. Also, $\mathrm{CO}$ was considered 1.38 times easy-to use than PO.

\section{Direct ophthalmoscopes versus smartphone-based ophthalmoscopes}

Beyond the comparison of $\mathrm{CO}$ and PO (direct ophthalmoscopes), Dunn et al [29] compared also these two devices to a non-mydriatic camera and three SF (PO+ iExaminer, an smartphone adaptor and D-EYE), using a questionnaire that ranged from 6 (lowest score) to 30 (highest score). One hundred and forty-six medical students had their perceived usefulness, ease of use, ease of view, confidence and quality of training measured with each of the 6 devices after a 10-minute practical training. SF had the highest score for perceived usefulness (24.81) when compared to non-mydriatic camera (22.45, $p<$ $0.001)$ and direct ophthalmoscopes (22.95, $p=0.006)$. For easier of use, SF also had a higher score (25.37) when compared to the previous 2 categories $(21.55, p<$ 0.001 ) and 22.96, $p<0.001)$. Regarding ease to view CO showed an inferior score when compared to the other 5 devices $(p<0.007)$; while confidence with $\mathrm{CO}$ only had difference with PO $(p=0.001)$, which this second obtained the highest confidence level, and no difference with the other devices. Quality of training had no difference among the 6 devices. Kim et al [30] also compared $\mathrm{CO}$ to D-EYE in terms of visualization of optic nerve and blood vessels, along with confidence, by second year MS after 1-h practical training. Among 101 students enrolled, $82.3 \%$ reported visualization of the optic nerve in an undilated pupil with the SF, while $48.5 \%$ reported the same with the traditional device $(p<0.0001)$. MS also performed better with the first device even with dilated pupils $(85.9 \%$ vs. $65.4 \%, p=0.0036)$. Ease of use $(4.25$ vs. $2.76, p<0.0001)$ and confidence (3.70 vs. $2.41, p<$ $0.0001)$ were also higher for D-EYE. Moreover, MS preferred the new device than the traditional one $(78.2 \%$ vs. $77.2 \%, p<0.0001)$. However, a study that compared CO to a 20 diopters lens plus smartphone camera [31] in identify the optic nerve head, macula and retina vessels found a different outcome. Among $137 \mathrm{MS}$ enrolled for the 20 to 25 -minute instruction in one device or another, they referred a higher quality of visualization of optic nerve head and macula in CO than in the SF, with less attempts need to identify the structures with $\mathrm{CO}$ $(2.7 \pm 2.3$ vs. $4.5 \pm 2.9, p<0.001)$. CO was preferred over the SF for $69 \%$ of MS, and $24 \%$ preferred this over CO. These studies have revealed that smartphone-based fundoscopy is an emerging technique for fundus examination teaching, but more investigation is needed before it become the choice method of teaching fundoscopy due to a variety of different SF devices and the useful of other non-traditional direct devices like wide field ophthalmoscopes.

Not restricted to direct or SF ophthalmoscopes, another useful technique of fundus examination is the non-mydriatic fundus photograph, which was evaluated in the emergency environment by Bruce et al [32] and Dunn et al [33] in terms of ophthalmoscopy skills and diagnostic accuracy. The first study [32] compared direct ophthalmoscope to non-mydriatic fundus photograph in an emergency environment. Among the 354 patients included, 239 fundus photographs (68\%) were reviewed: 125 of these $(35 \%)$ were considered helpful in the 
evaluation, 16 of 35 (46\%) relevant findings were identified. The sensitivity of fundus photographs in identify neurological emergency pathologies was $46 \%$ and specificity $91 \%$. The second study [33] enrolled 345 patients for fundus photograph, which 283 (45\%) were considered the method useful. The sensitivity for emergency physicians detect urgent conditions with fundus photograph evaluation was $40 \%$ and specificity was $82 \%$. These studies shows that, even with different devices, fundus evaluation is still a major point of concern on medical education due to a limited proficiency in the exam, which reflects in low diagnostic accuracy.

\section{Factors that influence long-term self-confidence}

Our study provides the longest follow-up comparison between $\mathrm{CO}$ an $\mathrm{PO}$ in terms of evaluate the main fundus structures after a practical training. Lee et al. [34], in a relatively similar study design, assessed self-confidence of second year MS with a 6-point Likert scale questionnaire, divided in groups of 8-9 students, pre- and posta single 90 -min session practical training in both $\mathrm{PO}$ and $\mathrm{CO}$. Of the session, only $40 \mathrm{~min}$ were dedicated to teach direct ophthalmoscopy. Of the 172 students that completed the pre-session survey and 108 that completed the post-session survey, an increase of the confidence in visualize the optic nerve was reported with the PO (1.21 vs. $4.48, p<0.001)$. Optic nerve was observed by $99.1 \%$ of MS with either devices. However, confidence with $\mathrm{CO}$, which was higher than $\mathrm{PO}$ before training $(2.30$ vs. $1.16, p<0.001)$, showed a worst performance after training (3.93 vs. 4.49, $p<0.001$ ). Moreover, 80 of 85 students reported preference for the PO device. Eight months after the training, 42 students were re-evaluated in their ophthalmoscopy skills. They performed fundoscopy in two patients. $57.1 \%$ of MS responded the evaluation correctly, and $40.5 \%$ responded incorrectly with $\mathrm{PO}$, while $9.5 \%$ responded correctly and $23.8 \%$ responded incorrectly with CO. Moreover, $97.6 \%$ and $33.3 \%$ visualized the optic nerve with the respective $\mathrm{PO}$ and $\mathrm{CO}$ devices.

In our casuistic, a superiority of $\mathrm{PO}$ was expected due to its larger field of view and magnification, but $\mathrm{CO}$ superiority 1 year after intervention was not expected as demonstrated by the studies previously described. Some hypothesis can be listed to explain these findings: (1) lower cost of conventional ophthalmoscopes models compared to the PanOptic, which facilitates ownership of the first one, (2) availability of conventional ophthalmoscopes in some sectors of our hospital and primarycare units, which propitiated MS contact with $\mathrm{CO}$ during the period but not with PO, (3) and the longest training session, when compared to other studies, would provide a better retention with $\mathrm{CO}$ than with $\mathrm{PO}$. Some aspects that influence the confidence in fundoscopy were investigate by Schulz et al [20], which compared MS of the 4th -year to MS of final year of medicine course. The authors found that the first group was more confident in perform the examination than the second group, and described the exposure to an abnormal fundus and the feedback on their ability in using the ophthalmoscope as the factors that influenced this outcome. Also, the authors suggested an early formal instruction, with a reinforcement in the final year, as an attitude to improved MS confidence in fundoscopy. Moreover, McNaught and colleagues [13] related the ownership of ophthalmoscopes by MS with the frequency that fundus examination was performed: among those who owned a device, $7.3 \%$ always performed fundoscopy, while $26.8 \%$ did half of the time and $66 \%$ occasionally. Among the group that did not owned an ophthalmoscope, only $4.3 \%$ always performed the exam, $17.4 \%$ did half of the time and $78.3 \%$ occasionally. These differences, however, were not statistically significant, which reflects that ownership of ophthalmoscope may not be a determinant factor for fundoscopy practice.

\section{Strengths}

Our study translated and validated to Portuguese a questionnaire that assessed the self-confidence of medical students in evaluate the most critical structures in eye fundus. This will provide a standardized methodology for future studies that aim to evaluate the same subject and allow comparison of the results.

Compared to literature, our training session is the longest to the best of our knowledge $(6 \mathrm{~h})$. In addition, our study provides the longest comparison of self-confidence of MS to exam eye fundus ( 1 year) with two different devices. This long term analysis allowed us to discuss factors that influenced the self-confidence with two different devices during the 1-year period, which will provide a basis for future interventions that aim to increase the confidence in MS handle an ophthalmoscope.

\section{Limitations}

One main issue about cross-cultural validation is the meaning of "equivalence" [35]: grammatical equivalence and automatic translation does not mean semantic equivalence necessarily, and adaptations must be made in order to keep it relevant and representative of the new culture; a failure in this item would generate an instrument that does not measure the same parameters of the original one. Furthermore, availability of native English-speakers for the back-translation sometimes is limited in some locations [26].

Because of Covid-19 outbreak and consequent social distancing, our results should be interpreted with certain caution. Several activities in our institution were suspended for a course of 3 months, with all the focus kept 
on emergency assistance, where clerks did not act during this period. Moreover, almost after 1 year of the pandemic, most practical activities were not fully resumed, which certainly impacted the total of patients' fundus examined by MS during the last year.

We were not able to measure students' self-confidence before practical training, and compared both intervention groups to a different control group, which limited a before-after analysis of the intervention. Also, we did not evaluate students' skills in fundus examination, that would provide additional information, given that selfconfidence not always correlate with performance. At 1year questionnaire re-application, PO group had a lower rate of answers, in opposition to the $\mathrm{CO}$ group, what could had constituted a bias. Ownership of ophthalmoscopes, which would help a more accurate explanation of our results, was not evaluated also.

\section{Conclusions}

In conclusion, medical students were more confident in use PO as an instrument to perform direct ophthalmoscopy immediately after practical training, but confidence level of $\mathrm{CO}$ was higher compared to PO 1 year after practical ophthalmoscopy training.

We suggest more studies with wide-field ophthalmoscope to better evaluate advantages and disadvantages of these devices in long-term on self-confidence, technique performance and diagnostic accuracy. Comparison with other emerging techniques of fundoscopy, like smartphone-based, would also provide additional information for the decision of the choice method to teach fundus examination to MS in medical schools.

\section{Abbreviations \\ MS: Medical students; SF: Smartphone-based ophthalmoscope; CO: Conventional ophthalmoscope group; PO: PanOptic ophthalmoscope group}

\section{Supplementary Information}

The online version contains supplementary material available at https://doi. org/10.1186/s12909-021-02942-y.

\section{Additional file 1.}

\section{Acknowledgements}

We thank Professor Stephen Hyslop and Dr. Chase Warner for the support with the translation process of the questionnaire; Alessandra Santos and all the Welch Allyn staff for the support with this project; and Capes/CNPQ for partially fund this project.

\section{Authors' contributions}

GA designed the project, collected, analyzed and interpreted data. RBF and AMA collected and interpreted data. JPCV interpreted data and revised the manuscript. All authors contributed with the manuscript and approved its final version.

\section{Authors' information}

GA is an ophthalmologist, with a master degree, and with his glaucoma fellowship in progress.
RBF and AMA are medical students.

JPCV $\mathrm{s}$ is an ophthalmologist, a glaucoma specialist, with a PhD, and associated professor of ophthalmology.

\section{Funding}

Hill-Rom / Welch Allyn partially funded this project with the ophthalmoscopes and publication fees.

Capes/CNPQ granted this project (process number 166074/2019-5)

\section{Availability of data and materials}

The datasets used and/or analyzed during the current study are available from the corresponding author on reasonable request.

All data generated or analyzed during this study are included in this published article and its supplementary information files.

\section{Declarations}

\section{Ethics approval and consent to participate}

This prospective cohort study was approved by the Ethics Committee of the University of Campinas and conducted in compliance with the Declaration of Helsinki. All procedures were fully explained and an informed consent was obtained from all participants.

\section{Consent for publication}

Not applicable.

\section{Competing interests}

Gabriel Ayub and José Paulo Cabral de Vasconcelos: research grant (Hill-Rom / Welch Allyn)

Rafael Boava Souza: Capes/CNPQ grant 166074/2019-5

Andrelisa Marina de Albuquerque: none

Received: 1 July 2021 Accepted: 15 September 2021

Published online: 26 September 2021

\section{References}

1. Flaxman SR, Bourne RRA, Resnikoff S, Ackland P, Braithwaite T, Cicinelli MV, et al. Global causes of blindness and distance vision impairment 1990-2020: a systematic review and meta-analysis. Lancet Glob Heal. 2017;5(12):e122134.

2. Petrushkin H, Barsam A, Mavrakakis M, Parfitt A, Jaye P. Optic disc assessment in the emergency department: a comparative study between the PanOptic and direct ophthalmoscopes. Emerg Med J. 2012;29(12):10078.

3. Tan AK, Mallika PS, Aziz S, Asokumaran T, Intan G, Faridah HA. Comparison between the PanOptic ophthalmoscope and the conventional direct ophthalmoscope in the detection of sight threatening diabetic retinopathy: the Kuching diabetic eye study. Malays Fam Physician. 2010;5(2):83-90.

4. Hutchinson A, McIntosh A, Peters J, O'Keeffe C, Khunti K, Baker R, et al. Effectiveness of screening and monitoring tests for diabetic retinopathy - a systematic review. Diabet Med. 2000;17(7):495-506.

5. Shuttleworth GN, Marsh GW. How effective is undergraduate and postgraduate teaching in ophthalmology? Eye. 1997;11(5):744-50.

6. Harding SP, Broadbent DM, Neoh C, White MC, Vora J. Sensitivity and specificity of photography and direct ophthalmoscopy in screening for sight threatening eye disease: the Liverpool diabetic eye study. Bmj. 1995; 311(7013):1131.

7. Hogarty DT, Hogarty JP, Hewitt AW. Smartphone use in ophthalmology: what is their place in clinical practice? Surv Ophthalmol. 2020;65(2):250-62. https://doi.org/10.1016/j.survophthal.2019.09.001.

8. Parrish RK, Tso MOM. Principles and guidelines of a curriculum for ophthalmic education of medical students: Presented by International Task Force on Ophthalmic Education of Medical Students - On behalf of the International Council of Ophthalmology (ICO). Klin Monbl Augenheilkd. 2006:223(SUPPL. 5):S1-S19.

9. Straatsma BR, Coscas GJ, Naumann GOH, Spivey BE, Taylor HR, Tso MOM. International ophthalmology strategic plan to preserve and restore visionvision for the future. Am J Ophthalmol. 2001;132(3):403-4.

10. Stern GA. Teaching ophthalmology to primary care physicians. Arch Ophthalmol. 1995;113:722-4. 
11. Succar T, Grigg J, Beaver HA, Lee AG. A systematic review of best practices in teaching ophthalmology to medical students. Surv Ophthalmol. 2016; 61(1):83-94. https://doi.org/10.1016/j.survophthal.2015.09.001.

12. Yusuf $\mathrm{H}$, Salmon JF, Patel CK. Direct ophthalmoscopy should be taught to undergraduate medical students - Yes. Eye. 2015;29(8):987-9.

13. McNaught A, Pearson RV. Ownership of direct ophthalmoscopes by medical students. Med Educ. 1992;26(1):48-50.

14. Mottow-Lippa L. Ophthalmology in the medical school curriculum: reestablishing our value and effecting change. Ophthalmology. 2009;116(7): 1235-6. https://doi.org/10.1016/j.ophtha.2009.01.012 e1.

15. Benbassat J, Polak BCP, Javitt JC. Objectives of teaching direct ophthalmoscopy to medical students. Acta Ophthalmol. 2012;90(6):503-7.

16. Wu EH, Fagan MJ, Reinert SE, Diaz JA. Self-confidence in and perceived utility of the physical examination: a comparison of medical students, residents, and faculty internists. J Gen Intern Med. 2007;22(12):1725-30.

17. Gupta RR, Lam W-C. Medical students' self-confidence in performing direct ophthalmoscopy in clinical training. Can J Ophthalmol. 2006;41(2):169-74. https://doi.org/10.1139//06-004

18. Cordeiro MF, Jolly BC, Dacre JE. The effect of formal instruction in ophthalmoscopy on medical student performance. Med Teach. 1993;15(4): 321-5.

19. Lippa LM, Boker J, Duke A, Amin A. A novel 3-year longitudinal pilot study of medical students' acquisition and retention of screening eye examination skills. Ophthalmology. 2006;113(1):133-9.

20. Schulz C, Hodgkins P. Factors associated with confidence in fundoscopy. Clin Teach. 2014;11(6):431-5.

21. McComiskie JE, Greer RM, Gole GA. Panoptic versus conventional ophthalmoscope. Clin Exp Ophthalmol. 2004;32(3):238-42.

22. Kelly LP, Garza PS, Bruce BB, Graubart EB, Newman NJ. Teaching Ophthalmoscopy to Medical Students (the TOTeMS Study). Am J Ophthalmol. 2013;156(5):1056-61.

23. Mackay DD, Garza PS, Bruce BB, Bidot S, Graubart EB, Newman NJ, et al. Teaching ophthalmoscopy to medical students (TOTeMS) I: A one-year retention study. Am J Ophthalmol. 2014;157(3):747-8

24. Haque R, Abouammoh MA, Sharma S. Validation of the Queen 's University ophthalmoscopy objective structured clinical examination checklist to predict direct ophthalmoscopy proficiency. Can J Ophthalmol. 2012;47(6): 484-8. https://doi.org/10.1016/j.jcjo.2012.09.003.

25. Beaton DE, Bombardier C, Guillemin F, Ferraz MB. Guidelines for the process of cross-cultural adaptation of self-report measures. Spine (Phila Pa 1976). 2000;25(24):3186-91.

26. Gjersing L, Caplehorn JR, Clausen T. Cross-cultural adaptation of research instruments: Language, setting, time and statistical considerations. BMC Med Res Methodol. 2010;10-13

27. Tsang S, Royse CF, Terkawi AS. Guidelines for developing, translating, and validating a questionnaire in perioperative and pain medicine. Saudi J Anesth. 2017;11(5):80-9.

28. Sousa VD, Rojjanasrirat W. Translation, adaptation and validation of instruments or scales for use in cross-cultural health care research: A clear and user-friendly guideline. J Eval Clin Pract. 2011;17(2):268-74.

29. Dunn HP, Kang CJ, Marks S, Witherow JL, Dunn SM, Healey PR, et al. Perceived usefulness and ease of use of fundoscopy by medical students: a randomised crossover trial of six technologies (eFOCUS 1). BMC Med Educ. 2021;21(1):1-9

30. Kim Y, Chao DL. Comparison of smartphone ophthalmoscopy vs conventional direct ophthalmoscopy as a teaching tool for medical students: The COSMOS study. Clin Ophthalmol. 2019;13:391-401.

31. Kohler J, Tran TM, Sun S, Montezuma SR. Teaching smartphone funduscopy with 20 diopter lens in undergraduate medical education. Clin Ophthalmol. 2021;15:2013-23.

32. Bruce $B B$, Thulasi $P$, Fraser $C L$, Keadey MT, Ward A, Heilpern $\mathrm{KL}$, et al. Diagnostic accuracy and use of nonmydriatic ocular fundus photography by emergency physicians: phase II of the FOTO-ED study. Ann Emerg Med. 2013;62(1):28-33. https://doi.org/10.1016/j.annemergmed.2013.01.010 e1.

33. Dunn HP, Teo KZ, Smyth JWP, Weerasinghe LS, Costello J, Pampapathi $P$, et al. Using non-mydriatic fundus photography to detect fundus pathology in Australian metropolitan emergency departments: a prospective prevalence and diagnostic accuracy study. Emerg Med Australas. 2021;33(2): 302-9.
34. John Y, Lee, Gallo RA, Alabiad CR. Evaluating the effectiveness of smallgroup training in teaching medical students integral clinical eye examination skills. J Acad Ophthalmol. 2020;12(1):e79-86.

35. Herdman M, Fox-Rushby J, Badia X. "Equivalence" and the translation and adaptation of health-related quality of life questionnaires. Qual Life Res. 1997;6(3):237-47.

\section{Publisher's Note}

Springer Nature remains neutral with regard to jurisdictional claims in published maps and institutional affiliations.
Ready to submit your research? Choose BMC and benefit from:

- fast, convenient online submission

- thorough peer review by experienced researchers in your field

- rapid publication on acceptance

- support for research data, including large and complex data types

- gold Open Access which fosters wider collaboration and increased citations

- maximum visibility for your research: over $100 \mathrm{M}$ website views per year

At BMC, research is always in progress.

Learn more biomedcentral.com/submissions 